\title{
Patient with false negative RT-PCR for COVID-19 referred to cancer hospital for lung cancer screening: A case report
}

Yadav $\mathrm{AK}^{1 *}$, Gnawali $\mathrm{S}^{2}$, Mandal $\mathrm{S}^{3}$, Shrestha $\mathrm{GB}^{4}$, Yuan $\mathrm{G}^{5}$

*Corresponding author:

Mr. Ajay Kumar Yadav, Ph.D. Scholar, Nuclear Medicine, The Second Affiliated Hospital of Chongqing Medical University, PR China

Email: ajay_bpkmch@hotmail.com ORCID

Information about the article:

Received: Nov 28, 2021

Accepted: Dec 25, 2021

Published online: Dec 31, 2021

Cite this article:

Yadav AK, Gnawali S, Mandal S, Shrestha GB, Yuan G. Patient with false negative RT-PCR for COVID-19 referred to cancer hospital for lung cancer screening: A case report. Journal of Biomedical Sciences. 2021;8(2):50-54

\section{Publisher}

Nepal Health Research Society, Bahundhara -6, Gokarnesowor Municipality, Kathmandu, Nepal

eISSN 2382-5545, ISSN 2676-1343 (Print)

(C) The Author(s). 2021

Content licensing: CC BY 4.0

\begin{abstract}
Background

Even though RT-PCR tests are generally considered the gold standard for diagnosing SARS-CoV-2, they are not without flaws, and the likelihood of detecting an infection varies depending on when the test is performed. There is chance of false negative due to different pitfalls. So there is essential of correlation of radiological characteristics, abnormalities in biochemical tests and symptoms of suspected patient during COVID-19 epidemic.
\end{abstract}

\section{Case presentation}

Herein, we report a 42-year-old male patient with highgrade fever, dry cough, headache and dizziness. He went for the RT-PCR test two times and reported negative. On the chest X-Ray, there was opacity on both lungs and referred to cancer-hospital for lung-cancer screening. The patient underwent chest-HRCT and laboratory tests for further evaluation and was identified as typical COVID-19 findings. Then the patient was isolated and treatment of given according to COVID-19 treatment guidelines

\section{Conclusion}

It is concluded that a clinically symptomatic patient with typical chest HRCT and abnormal lab findings for COVID19 should be considered as a COVID-19 patient and isolated even with two negative RT-PCR tests.

\section{Keywords}

COVID-19, HRCT, lung cancer, Nepal, pneumonia, RTPCR 


\section{Background}

COVID-19 is an infectious disease first identified in Wuhan, China. It is caused by severe acute respiratory syndrome coronavirus 2 (SARS-CoV-2). The global pandemic of COVID-19 brought an unprecedented number of infectious patients requiring admission to the hospital's isolation ward. In addition, the indications of COVID-19 can be non-specific, so investigative confirmation in the hospital is often needed after detecting SARS-CoV-2 RNA sequences by reverse transcription (RT-PCR) of a clinical sample.

SARS-CoV-2 virus-infected patients must go for nasopharyngeal or oropharyngeal RT-PCR double-swab test and Chest radiography for the first step and the further detail evaluation. HRCT chest and biochemical laboratory tests are recommended in case of inconsistency between characteristics of clinical history and radiological findings [1]. The sensitivity of nasopharyngeal or oropharyngeal RTPCR swab test applied to respiratory tract specimens are only $60 \%$ to $70 \%$ due to different practical causes (reagents, sample transport conditions, etc.), inherent limits like viral load in dissimilar anatomic sites and sampling procedures [2].

Herein we report a COVID-19 suspect case with a two-time negative RT-PCR double swab test for COVID-19, finally diagnosed as interstitial COVID-19 pneumonia and treated according to COVID-19 treatment protocol and recovered.

\section{Case presentation}

According to history taken from the patient and his reports, we reported a 42-year-old male patient from rural Myagdi district of Nepal presenting with high-grade fever, dry cough, headache, and dizziness on August 10, 2021, during the second phase of the second phase COVID-19 pandemic. The patient had no history of diabetes and hypertension in the past.

He underwent an RT-PCR test at his home district's local COVID-19 screening centre and was reported as negative in the RT-PCR test. After that, he was referred to Lumbini Zonal hospital for further evaluation and treatment. The patient underwent an RT-PCR test and Chest X-Ray at Zonal Hospital and again reported a negative RT-PCR test. There was opacity on the chest X-Ray (figure 1) on both lungs, and the patient was referred to a cancer hospital for lung cancer screening.

At BP Koirala Memorial Cancer Hospital, the patient underwent HRCT chest and biochemical laboratory tests for further evaluation. The chest High-Resolution Computed Tomography (HRCT) indicated Ground Grass Opacity (GGO) with crazy paving a typical COVID-19 interstitial pneumonia on August 15, 2021 (figure 2).

In the biochemical laboratory test (August 15, 2021), there was an elevation in Leukocyte (Total WBC count), Neutrophil, Bilirubin Direct (BD), Bilirubin Total (BT), AST, ALT and LDH. There was Lymphocytopenia noted. We followed up with regular laboratory tests of that patient at regular intervals. On August 18, 2021, there was an elevation of random glucose level despite no history of diabetes in the past. On August 25, 2021, a low count was found in eosinophil and monocyte. The laboratory parameters of the patients on different dates during prognosis are summarised in table-1. These laboratory parameters findings are typical signs of COVID-19 patients.

\begin{tabular}{|c|c|c|c|c|c|}
\hline \multicolumn{6}{|c|}{$\begin{array}{l}\text { Table 1: Laboratory parameters of COVID-19 patient } \\
\text { on different date during prognosis }\end{array}$} \\
\hline Date (2021) & Aug-15 & Aug-18 & Aug-21 & Aug-25 & Sep-12 \\
\hline Hemoglobin & $15(\mathrm{~N})$ & $12.9(\mathrm{~L})$ & $13(\mathrm{~L})$ & $13.5(\mathrm{~L})$ & $14.5(\mathrm{~N})$ \\
\hline $\begin{array}{l}\text { Leucocyte } \\
\text { (WBC) }\end{array}$ & $\begin{array}{l}112000 \\
(\mathrm{H})\end{array}$ & $\begin{array}{l}79300 \\
(\mathrm{H})\end{array}$ & $57000(\mathrm{H})$ & $8100(\mathrm{~N})$ & $5500(\mathrm{~N})$ \\
\hline Neutrophil & $41(\mathrm{~N})$ & $90(\mathrm{H})$ & $90(\mathrm{H})$ & $85(\mathrm{H})$ & $67(\mathrm{~N})$ \\
\hline Lymphocyte & $08(\mathrm{~L})$ & $05(\mathrm{~L})$ & $08(\mathrm{~L})$ & $10(\mathrm{~L})$ & $29(\mathrm{~N})$ \\
\hline Eosinophil & & & $01(\mathrm{~N})$ & $00(\mathrm{~L})$ & $03(\mathrm{~N})$ \\
\hline Monocyte & & & $01(\mathrm{~L})$ & $01(\mathrm{~L})$ & $02(\mathrm{~N})$ \\
\hline Glucose R & $123(\mathrm{~N})$ & $171(\mathrm{H})$ & $145(\mathrm{H})$ & & \\
\hline Blirubin Total & $1.94(\mathrm{H})$ & & & & \\
\hline Bilirubin & $0.51(\mathrm{H})$ & & & & \\
\hline \multicolumn{6}{|l|}{ Direct } \\
\hline SGOT/AST & $62(\mathrm{H})$ & & & & \\
\hline SGPT/ALT & $41(\mathrm{H})$ & & & & \\
\hline LDH & $538(\mathrm{H})$ & $458(\mathrm{H})$ & $412(\mathrm{H})$ & $318(\mathrm{H})$ & $213(\mathrm{~N})$ \\
\hline
\end{tabular}

Abbreviations; N=Normal count, H=High count and L=Low count

Then the patient was admitted to the COVID isolation ward of BP Koirala Memorial cancer hospital and treated according to COVID-19 BPKMCH treatment guidelines. [BPKMCH COVID-19 treatment guidelines 1) Antibiotics; Inj. Piperacillin/Tazobactum - 4-5mg - IV/TDS x 7-Days or Inj. Xone - 1mg - IV/BD x 7-Days, 2) Steroids; - Dexona 8mg - IV/TDS, 3) Antipyretics - Tabs Paracetamol 500mg QID - 7 days, 4) Anticoagulant - Clexane 40-60mg SC/OD 5) Multivitamins - Tabs Immunin - Oral/OD - 2 weeks, 5) Anti-infection - Tabs Ivermectin 12mg Oral/OD - 3Days, 6) Inj. Lantus (Insulin Glargine) - SC/100IU/ml Injection $10 \mathrm{ml}$ and 7) additional treatment as per symptomatic ]. The patient was followed up in the isolation ward for the next 30 days with regular radiological and laboratory tests. On September 12, 2021, almost all related diagnostic tests were normal and showed that patient recovered from COVID-19. After the patient got physically and mentally stable, on September 13, 2021, the patient was discharged from the isolation ward. We regularly followed up with the patient on phone conversations weekly for one month. The patient reported no clinical complaints.

\section{Discussion}

Earlier research studies showed that there is a chance of false-negative of the RT-PCR dual swab test which may be due to insufficient amounts of SARS-CoV-2 virus accumulations in patients with several samples collected during different stages of infection. It is recommended that the consequent clinical assessment of every patient guarantee that RT-PCR outcomes are not the only reason to exclude COVID-19 disease [3]. Disease control and prevention centres reported that "Binax-NOW antigen test 
JBS 2021;8(2):50-54
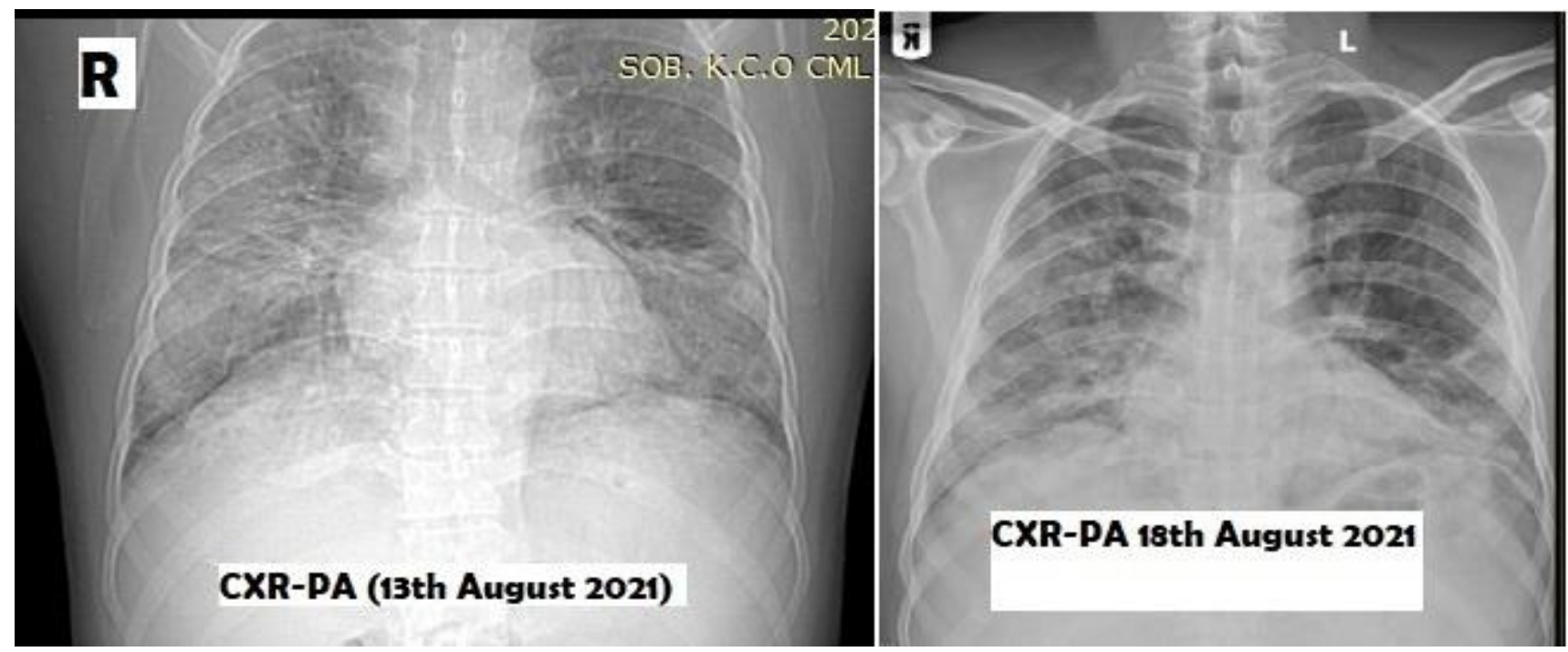

Figure 1 (above) shows chest X-Ray of 42 years male RTPCR negative patient bilateral opacity seen in both lungs (August 13) and decrease of infection seen on August 18, 2021.
Figure 2 (below) shows HRCT of 42 years male RT-PCR negative patient with CT severity score was 21 reported as Severe, GGO appearance with crazy paving on August 15, 2021. Patient totally recovered from COVID.
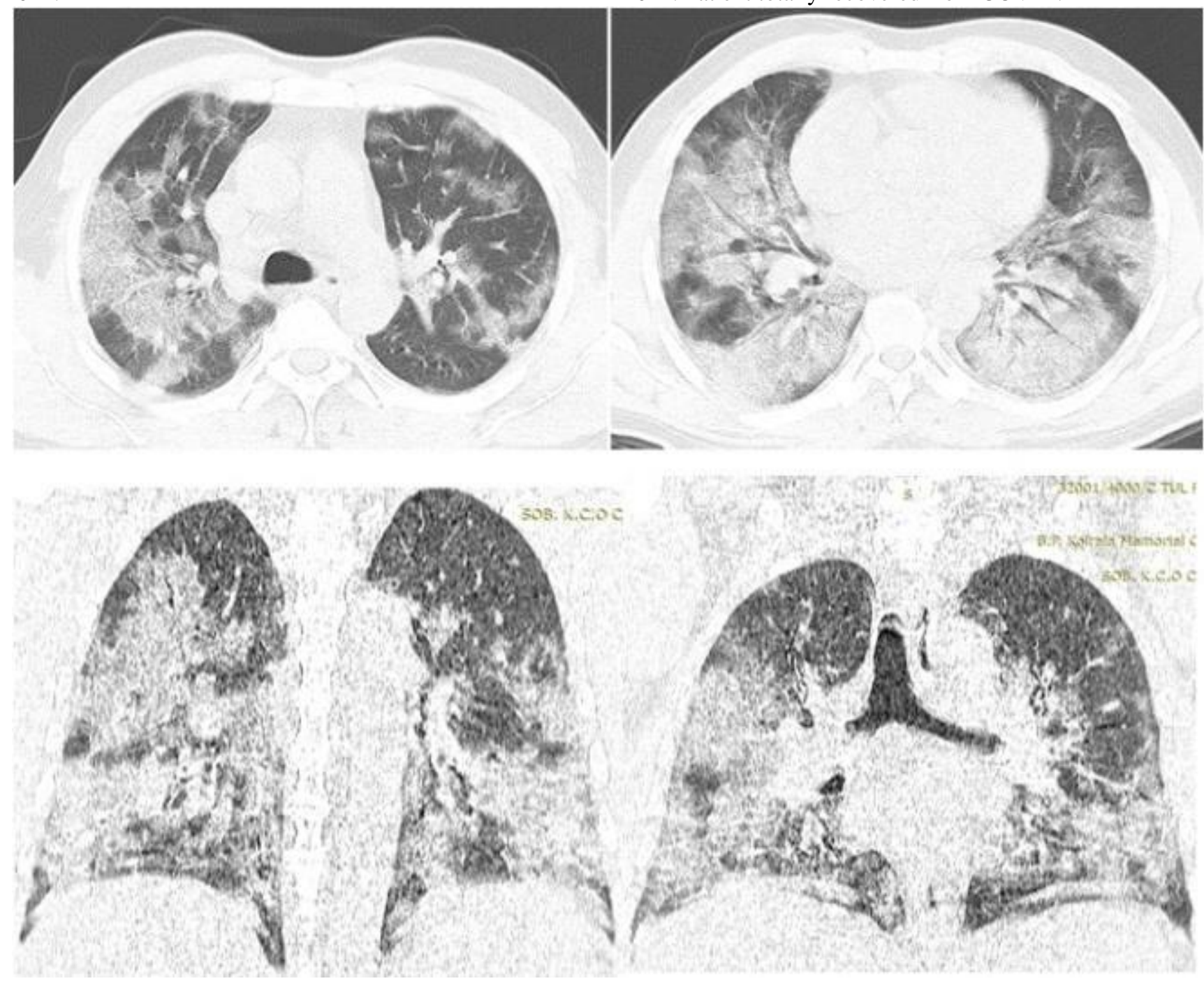
performance compared to the real-time RT-PCR was better for such specimens with a positive viral culture than all samples, with a sensitivity of $92.6 \%$ for samples of symptomatic people and $78.6 \%$ for those of asymptomatic people" [4]. The reduced number of lymphocytes and the augmented levels of $\mathrm{LDH}$, neutrophil and liver function test stages are related to SARS-COV-2 related interstitial pneumonia. This can be an added investigative tool in patients with highly suspicious double-tested and highly questionable clinics. Patients with SARS-COV-2 symptoms should be isolated [5].

Our case study showed typical COVID-19 features in the HRCT chest (ground-glass opacity (GGO) with crazy paving). There was an elevation in Leukocyte, Neutrophil, Liver Function Test (LFT) and LDH with Lymphocytopenia. During prognosis, the elevation of random glucose levels was an additional feature. Case reports confirm that diabetes is induced simultaneously as acute SARS-CoV2 infection or within weeks to months after recovery from the disease. [6].

\section{Conclusion}

We conclude that a symptomatic patient with chest HRCT with typical COVID-19 pneumonia features with altered laboratory findings i.e. elevation in Leukocyte, Neutrophil, Liver Function Test (LFT) and LDH with Lymphocytopenia should be quarantined even with two negative RT-PCR tests.

\section{Abbreviations}

High Resolution Computed Tomography (HRCT), Liver Function Test (LFT), Corona Virus Disease 2019 (COVID19), severe acute respiratory syndrome coronavirus 2 (SARS-CoV-2), Lactate Dehydrogenase Assay (LDH), reverse transcription- polymerase chain reaction test (RTPCR)

\section{Acknowledgments}

All the authors contributed equally to the study. We would like to thank the Department of Radio-diagnosis, Imaging and Nuclear Medicine and the Department of pathology for the swift and efficient support to make this work possible.

\section{Authors' contribution}

a. study planning: AKY, YG

b. case report: $\mathrm{SG}, \mathrm{AKY}$

c. follow up: SG

d. interpretation: AKY, SG, SM

e. manuscript writing: AKY, SG

f. manuscript revision: $Y G, A K Y$, GBS

g. final approval: AKY, NG, SM, GBS, YG

h. agreement to be accountable for all aspects of the work: AKY, NG, SM, GBS, YG

\section{Funding}

No funding was received.

\section{Availability of data and materials}

Figures of this case report are available as part of the article, and no additional image files are required.

\section{Consent for publication}

In line with the 1975 Helsinki Declaration on patient right's consent was sought and obtained from the patient, ethical approval was granted by the committee of Crystal Specialist Hospital. No patient nametag or any form of confidential personal information is compromised in this manuscript; a copy of the approval letter is available on demand by the editor.

\section{Competing interests}

All authors declare no conflicts of interests or competing interests concerning the material in this manuscript.

\section{Publisher's Note}

NHRS remains neutral with regard to jurisdictional claims in published maps and institutional affiliations.

The publisher shall not be legally responsible for any types of loss, actions, claims, proceedings, demand or costs or damages whatsoever or howsoever caused arising directly or indirectly in connection with or arising out of the use of this material.

\section{Author information}

${ }^{1}$ Ajay Kumar Yadav, Department of Nuclear Medicine, The Second Affiliated Hospital of Chongqing Medical University, PR China ORCID

${ }^{2}$ Suman Gnawali, Technologist BMIT, Department of Radiology \& Nuclear Medicine, BP Koirala Memorial Cancer Hospital, Bharatpur, Nepal ORCID

${ }^{3}$ Sandip Mandal, Technologist BMIT, Department of Radiology \& Nuclear Medicine, BP Koirala Memorial Cancer Hospital, Bharatpur, Nepal ORCID

${ }^{4}$ Gyan Bahadur Shrestha, Senior Consultant, Department of Radiology \& Nuclear Medicine, BP Koirala Memorial Cancer Hospital, Bharatpur, Nepal ORCID

${ }^{5}$ Yuan Gangbiao, MD, Ph.D. Professor, Department of Nuclear Medicine, The Second Affiliated Hospital of Chongqing Medical University, PR China ORCID

\section{References}

1. Kooraki S, Hosseiny M, Myers L, Gholamrezanezhad A. Coronavirus (COVID-19) Outbreak: What the Department of Radiology Should Know. J Am Coll Radiol. 2020; 17(4):447-451.

https://doi.org/10.1016/j.jacr.2020.02.008 
2. Yang $\mathrm{Y}$, Minghui $\mathrm{Y}$, Chenguang S, Fuxiang W, Jing Y, Jinxiu L. et al. Evaluating the accuracy of different respiratory specimens in the laboratory diagnosis and monitoring the viral shedding of 2019-nCoV infections. medRxiv. 2020;02.11.20021493; https://doi.org/10.1101/2020.02.11.20021493

3. Jamil N. K, Nathan Z, Clayton M, Kanti P, Muhammad N K, Abhaya P. et al. False negative rate of COVID-19 PCR testing: a discordant testing analysis. Virol J. 2021;18:13

https://doi.org/10.1186/s12985-021-01489-0

4. Centers for Diseases Control and Prevention (CDC) posted an article entitled Evaluation of Abbott BinaxNOW Rapid Antigen Test for SARS-CoV-2 Infection at Two CommunityBased Testing Sites, Pima County, Arizona, November 3-17, 2020. Internet [online 2021] [cited 22 January 2021]. Available from: https://www.cdc.gov/mmwr/volumes/70/wr/mm7 $\underline{003 \mathrm{e} 3 . \mathrm{htm}}$

5. Orlacchio A, Gasparrini F, Roma S, Ravà MS, Salvatori E, Morosetti D, et al. Correlations between chest-CT and laboratory parameters in SARS-CoV-2 pneumonia: A single-center study from Italy. Medicine (Baltimore). 2021;(4) 9;100(14):e25310. https://doi.org/10.1097/MD.0000000000025310

6. Sathish T, Kapoor N, Cao Y, Tapp RJ, Zimmet $\mathrm{P}$. Proportion of newly diagnosed diabetes in COVID-19 patients: A systematic review and meta-analysis. Diabetes Obes Metab. 2021; 23(3):870-874.

https://doi.org/10.1111/dom.14269 